\title{
DESICCATION RESISTANCE OF CHIRONOMID LARVAE
}

\author{
JAN FROUZ ${ }^{1, *}$ and JOSEF MATĚNA ${ }^{2}$ \\ ${ }^{1}$ CAS, Biology Centre, Inst. of Soil Biology, Na Sádkách 7, České Budějovice, CZ37005, Czech Republic \\ ${ }^{2}$ CAS, Biology Centre, Hydrobiological Inst., Na Sádkách 7, České Budějovice, CZ37005, Czech Republic \\ *Corresponding author: frouz@upb.cas.cz
}

\section{ABSTRACT}

\begin{abstract}
Resistance to desiccation in larvae of eight species of aquatic, semiaquatic and terrestrial chironomids (Pseudodiamesa branickii, Macropelopia sp., Prodiamesa olivacea, Micropsectra sp., Chironomus riparius, Chironomus dorsalis, Metriocnemus martini and Camptocladius stercorarius) was studied. The larvae were desiccated in exicator at constant conditions $\left(15^{\circ} \mathrm{C}, 80 \% \mathrm{RH}\right)$ and changes in moisture and body water content was recorded. The LD-50 for loss of body water was calculated. The lowest resistance to loss of body water was found in larvae from subfamilies Tanypodinae and Diamesinae Macropelopia sp. and P. branickii. They survived loss of 49.7 and $56.6 \%$ of original water content (presented values are LD-50). On the other hand the highest resistance to water loss was found in C. dorsalis. M. martini and C. stercorarius. The larvae of these species may survive loss of $67.4,76.6$ and $84.2 \%$ of original water content. Nevertheless the survival time under experimental conditions depends more closely on larval size than on lethal level of water loss. The smaller larvae desiccated faster and perished sooner than large ones despite they tolerate higher loss of body water.
\end{abstract}

Keywords: Chironomidae, dessication, drought tolerance, ecophysiology, aquatic, terrestrial

\section{Introduction}

Desiccation of the environment is an important factor that may cause catastrophic extinction of chironomid larvae in some aquatic or even terrestrial habitats (McLachlan 1983; Delettre 1986). Larvae of chironomids, both aquatic and terrestrial, have strongly reduced abilities to reduce water loss through cuticle (Buck 1965; Delettre 1988). Except of behavioural adaptations (migration etc.) tolerance to loss of body water is the main physiological mechanism of drought resistance. An extreme drought resistance was found in larvae of Polypedilum vanderplancki Hinton which can survive loss of $97 \%$ of water content of active larvae. At this stage the larvae can be kept in completely dry air and recovered even after 18 years, they survive exposure to temperatures from $-270{ }^{\circ} \mathrm{C}$ to $+120^{\circ} \mathrm{C}$. (Hinton 1951, 1960a, b; Adams 1985). This desiccation tolerance is not fixed to some larval instar and may repeat up to 10 times during larval development (Hinton 1960a). Nevertheless also other chironomid larvae, living in periodically desiccating water bodies such as Paraborniella tonnoiri, Polypedilum dewulfi and other, can survive substantial loss of body water (Jones 1975; Adams 1985). The main questions addresed in this study are as follows. Which is the resistance to loss of water body in chironomid larvae that are not adapted for living in frequently desiccating environment? Does this resistance correspond to phylogenetic position of species or habitat of the larvae?

\section{Material and Methods}

The larvae of eight chironomid species were studied. The larvae were sampled in the field by various techniques, aquatic larvae usually by sieving of the sediment, terrestrial larvae using soil sampling and consequent Tullgren extraction (Table 1). The larvae were kept starved in water in refrigerator for 48 hours before measurements, to exclude matter loss by defecation during measurement. The larvae were picked up from the water. Remnants of water were removed by filter paper and larvae were located individually in the case of larger species and small groups in smaller ones in small dry plastic chambers of known weight. The larvae were weighed together with chambers on micro balance Sartorius, accuracy $10^{-5} \mathrm{~g}$. The larvae were located individually into a small plastic chamber and exposed in exicator at $15{ }^{\circ} \mathrm{C}$ and $80 \%$ relative humidity. Constant relative humidity was kept using water glycerin solution. After a certain time, depending on larval size and desiccation resistance, the larvae were weighed again in the same manner as for the first time. The chambers were filled with water, kept for 12 hours at $15^{\circ} \mathrm{C}$, and recovery of larvae was regularly observed. Frequently the larvae were inactive and swollen in chambers, but became active some time (from minutes to hours) after water addition. All larvae that became active during 12 hours after water addition were assumed as recovered. After 12 hours all larvae were dried to constant weight $\left(60^{\circ} \mathrm{C}\right.$ for 6 hours $)$ and dry weight was determined. The tare of chamber was checked once again. The exicator weight and larval recovery was studied at least 5 times for each species. For each larva or group of larvae in small species, original moisture $(\mathrm{OM})$, moisture at the end of desiccation (FM) and loss of original moisture at the end of desiccation (LM) were calculated as follows (all the parameters were expressed in \%):

$$
\begin{aligned}
& O M=f w \times 100 / d w \\
& F M=e w \times 100 / d w \\
& L M=(e w-d w) \times 100 /(f w-d w)
\end{aligned}
$$


Table 1 Body water content, fresh weight, and desiccation LD50 for water content and loss of original water content for larvae of eight chironomid species. Statistically homogenous groups are marked by the same letters $(P<0.05, A N O V A)$.

\begin{tabular}{|c|c|c|c|c|c|}
\hline Subfamily/Species & Habitat & Water content & Fw [mg] & LD50 water content & LD50 water loss \\
\hline \multicolumn{6}{|c|}{ Tanipodinae } \\
\hline Macropelopia sp. & streem & $78.7 \pm 0.8$ & $10.45 \pm 17.79$ & $60.8 \pm 4.29 a$ & $49.7 \pm 4.80 \mathrm{a}$ \\
\hline \multicolumn{6}{|c|}{ Diamesinae } \\
\hline Pseudodiamesa branickii (Nowicki 1873) & streem & $81.9 \pm 0.8$ & $17.46 \pm 28.60$ & $53.6 \pm 2.6 b$ & $56.6 \pm 3.2 \mathrm{a}$ \\
\hline \multicolumn{6}{|c|}{ Prodiamesinae } \\
\hline Prodiamesa olivacea (Meigen 1818) & streem & $75.4 \pm 0.7$ & $6.70 \pm 2.10$ & $49.6 \pm 14.6 b$ & $66.6 \pm 15.0 \mathrm{ab}$ \\
\hline \multicolumn{6}{|c|}{ Chironominae } \\
\hline Micropsecra sp. & streem & $69.3 \pm 0.6$ & $1.97 \pm 1.33$ & $55.1 \pm 1.6 b$ & $64.7 \pm 2.3 b$ \\
\hline Chironomus riparius (Meigen 1804) & broom & $82.5 \pm 0.8$ & $8.69 \pm 1.85$ & $41.6 \pm 3.4 c$ & $70.6 \pm 3.9 b c$ \\
\hline Chironomus dorsalis (Meigen 1818) & rain pool & $87.2 \pm 0.8$ & $3.88 \pm 1.39$ & $41.1 \pm 4.8 \mathrm{~cd}$ & $67.4 \pm 5.1 b c$ \\
\hline \multicolumn{6}{|c|}{ Orthocladinae } \\
\hline Metriocnemus martini (Thieneman 1921) & phytothelma & $81.7 \pm 0.8$ & $0.46 \pm 0.12$ & $40.6 \pm 2.1 d$ & $72.6 \pm 2.6 c$ \\
\hline Camptocladius stercorarius (De Geer 1776) & dung-soil & $74.8 \pm 0.7$ & $0.83 \pm 0.07$ & $36.9 \pm 28.2 \mathrm{abcd}$ & $84.2 \pm 26.5 \mathrm{abc}$ \\
\hline
\end{tabular}

where $\mathrm{fw}$ is fresh weight before exposition to exicator, ew is weight after exposition in exicator and dw is dry weight. For each sampling time the number of recovered and dead larvae were recorded (Fig. 1). Based on these dates the LD50 for FM, LM were fitted using program for evaluation of acute toxicity test using COSTAT.

To asses hygroscopic sorption of bodies of chironomid larvae, dry dead larvae of Chironomus riparius of known weight were located in exicators with various relative humidities (from 100 to $60 \%$ at $15{ }^{\circ} \mathrm{C}$ ) and after 12 hours their final weight was measured. Each measurement was repeated three times.

\section{Results}

From the species tested, the lowest resistance to loss of body water was found in larvae from subfamilies Tanypodinae and Diamesinae Macropelopia sp. and P. branickii; they survived loss of 49.7 and $56.6 \%$ of the original water content (presented values are LD-50). On the other hand the highest resistance to water loss was found in C. stercorarius, M. martini and C. dorsalis; the larvae of these species may survive loss of $84.2,72.6$ and $67.4 \%$ of original water content. When the LD-50 for water content is considered, order of the most resistant species remains the same. Some changes occur on the most sensitive tail. Macropelopia sp. is the most sensitive, but in Micropsectra sp., P. branickii and P. olivacea appear. Nevertheless the differences between these species were not significant (Table 1). As far as comparison of terrestrial semiaquatic and aquatic species is concerned, the terrestrial and semi-aquatic species seem to tolerate higher loss of original water content than most resistant aquatic species from the genus Chironomus, but this dif- ference was significant only for semiaquatic M. martini. The high LD50 for loss of original water content was connected more likely with low original water content than with high resistance to low water content per se (Table 1).

Resistance to desiccation, expressed as both loss of original water content and water content per se, did not correspond with survival time under experimental conditions. For example in P. branickii the LD50 of both above mentioned desiccation parameters was reached after 10 hours (Fig. 1), but in M. martini after less than 4 hours. Thus under experimental conditions all larvae tested finally died and the survival time depended more closely on size of larvae than on ability to survive water loss. Nevertheless this is not likely to be true in environment that is more saturated with water. The tissues of the chironomid larvae absorb hygroscopically some water from air and thus for individual conditions of temperature and relative humidity some water content in the larval body can be found, that is in equilibrium with these conditions. For example in $20^{\circ} \mathrm{C}$ and $100 \%$ relative humidity this equilibrium water content of body of C. riparius is above $51 \%$ (Fig. 2). That means, this equilibrium water content is higher than LD50 water content for C. ripari$u s$. So it is very likely that larvae of $C$. riparius may survive outside of water in conditions when the air relative humidity reaches $100 \%$. In conclusion, in the simulation when the surrounding air is close to saturation the larvae with higher desiccation resistance should not reach lethal level of water content in the body.

This hypothesis is supported by the field observation that living larvae of $C$. drosalis were collected from mud in dried rain pool. The mud was transported into laboratory and it was observed that the larvae may survive in refrigerator $\left(\right.$ at $\left.10^{\circ} \mathrm{C}\right)$ at least one week in the mud. 


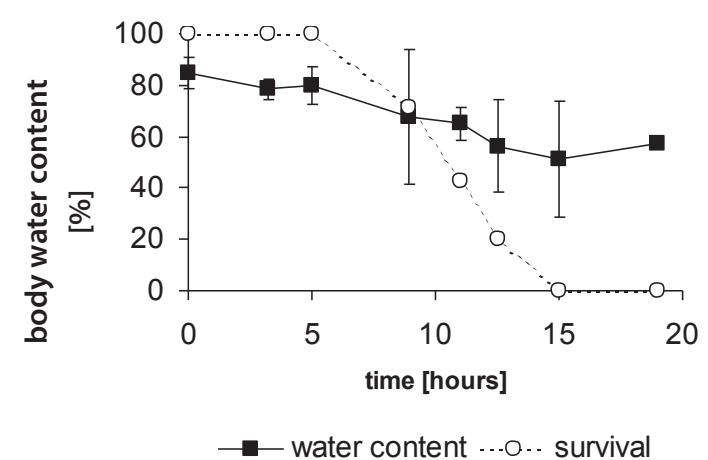

Fig. 1 Changes of body water content and frequency of survival during desiccation of Prodiamesa branickii larvae, bars represent SD.

\section{Discussion}

The lethal dose of desiccation in the species investigated in this study varied from 50 to $84 \%$ of original water content. Considering the literature data about Polypedilum wanderplanki, we can see that desiccation resistance is highly variable among chironomids and lethal water loss may vary from 50 to $93 \%$ of original water content (Hinton 1951, 1960a, b). Nevertheless the ability to survive loss of half or original water content seems to be quite common among chironomids.

The distribution of desiccation resistance among investigated species seems to indicate that this ability may correspond somehow to phyletic position of the species. Namely Tanipodinae and Diamesinae seem to be less resistant than Orthocladinae and Chironominae, nevertheless the number of investigated species is not enough to test this hypothesis.

From species considered in this study only, the literature data about desiccation resistance are available only for C. dorsalis. Buck (1965) mentioned for this species that it could survive loss of $50 \%$ of original water content. In our study the lethal water loss was found to be higher, about $70 \%$. This discrepancy seems to be apparently caused by different methodologies. Buck used simple observation to determine larval survival. The larvae of Chironomus that lose about $50 \%$ of original water content are swollen, immobile, dark and without turgor. At this stage it is not possible to recognize by simple observation, whether or not the larva is alive or dead. After addition of water larvae reach turgor again and some of them become active. So yet after this recovery dead and living larvae could be distinguished.

The larvae of all species tested finally died under experimental conditions and survival time seems to correspond more closely to larval size than to resistance to water loss. This may imply the question if the desiccation resistance has some ecological interpretation. Most of the larvae survive dry period in some porous media such as soil mud etc. (Hinton 1951; Jones 1975; Delettre 1988; Jackson and McLachlan 1991). The relative humidity of soil air is typically higher than air humidity above surface and is fre-

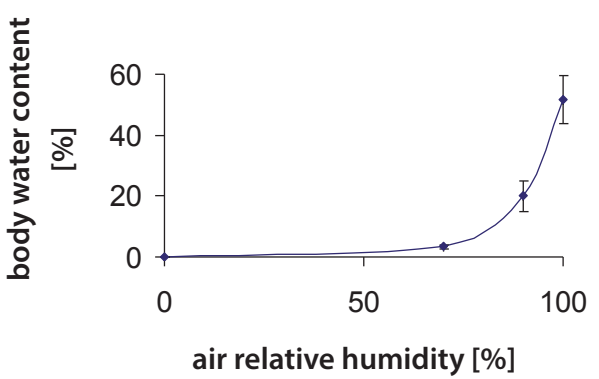

Fig. 2 Sorption of water by the dead dry bodies of Chironomus riparius in air with various relative humidity, bars represent SD.

quently close to $100 \%$ (Brady and Weil 2007). Our results indicate that water is not only evaporated from the larval body but the bodies of chironomid larvae also absorb hygroscopically some water from air. Due to combination of these two processes, some equilibrium water content exists for given condition of relative humidity and temperature. It means if the larvae desiccate, their water content does not decrease below this threshold. If this equilibrium point is above the lethal water content of the larvae, we can expect that larvae can survive in given moisture conditions. For example, dead body of C. riparius, located in the air with $100 \%$ relative humidity, absorbs by various physical processes water that represents more than $50 \%$ of larval weight. Because lethal water content is below this value, it is very likely that $C$. riparius larvae may survive in wet mud or soil. We can even expect that species that have LD50 for water content below 50 may survive in wet mud or wet soil. This assumption was verified by observation of C. dorsalis (this study) and M. martini (Zavřel 1941) and it is true of course also for terrestrial species $C$. stercorarius for which the soil is normal environment. Jackson and McLachlan (1991) mentioned also several other species, which may survive in wet peat.

The decrease of body water content, which is in equilibrium with air humidity rapidly decreased in unsaturated air. So migration to wetter part of soil or formation of any barrier (tubes, cocoons, etc.) that may help to keep wetter conditions nearby the body may be important for survival of larvae in desiccating environment (Jones 1975; Delettre 1988). The important role of cocoons was documented for P. tonnoiri that may survive whole dry summer period in cocoons in the soil but die in few minutes in open air (Jones 1975). In nature the situation is more complicated than balance between body water content and air moisture described above. Many processes with different power bound the water in soil and similar porous media. Part of this water can be taken by insects in soil either by physical, for example osmotic, processes or by active transport of water (Ghiljarov 1949; Prosser 1973). Bounded water may occur in soil for example as capillary, surface or hygroscopic water. These powers can be integrated as $\mathrm{pF}$ value, which is sucking power nec- 
essary to take water from soil. The amount of water and power that bound this water in soil depends on soil moisture but also on other soil properties (clay content, salinity, etc.) (Brady and Weil 2007). Thus study resistance of chironomid larvae to various levels of $\mathrm{pH}$ may be how to receive complex and ecologically relevant information about desiccation resistance of individual species.

\section{REFERENCES}

Adams S (1985) Cryptobiosis in Chironomidae (Diptera) - two decades on. Antenna 8: 58-61.

Brady NC, Weil RR (2007) The nature and properties of soils. Upper Saddle River, New Jersey, Prentice-Hall.

Buck JM (1965) Hydratation and respiration in chironomomid larvae. J Insect Physiol 11: 1503-1516.

Delettre YR (1986) La colonisation de biotopes multiples: une alternative à la résistance in situ aux conditions mésologiques défavorables. Cas de Limnophyes minimus (Mg.), Diptére Chironomidae à larves édaphiques des landes armoricaines. Revue d'Ecologie et Biologie du Sol 23: 29-38.
Delettre YR (1988) Flux d’évaporation corporelle et resistance á la desiccation chey les larves de guelques Chironomidae terrestres (Diptera). Revue d'Ecologie et Biologie du Sol 25: 129-138.

Ghiljarov MS (1949) Osobjenosti pochvi kak sredy obitanija i jej znachenie v evolucii nasekomich, Inzavatelsvo Akademii Nauk SSSR, Moscow.

Hinton HE (1951) A new chironomid from Africa, the larva of which can be dehydrated without injury. P Zool Soc London 121:371-380.

Hinton HE (1960a) Cryptobiosis in the larva of Polypedilum vanderplanki Hint. (Chironomidae). J Insect Physiol 5: 288-300.

Hinton HE (1960b) A fly larva that tolerates dehydratation and temperature from $-270{ }^{\circ} \mathrm{C}$ to $+120{ }^{\circ} \mathrm{C}$. Nature 188: $336-337$.

Jackson JM, McLachlan AJ (1991) Rain pools on peat moorland as island habitats for midge larvae. Hydrobiologia 209: 59-65.

Jones RE (1975) Dehydratation in an Australian rockpool chironomid larva Paralauterborniella tonnoiri. J Entomol 49: 111-119.

McLachlan AJ (1983) Life-history tactics of rain pool dwellers. J Anim Ecol 52: 545-561.

Prosser CL (1973) Comparative animal physiology, W. B. Sauders company, Philadelphia.

Zavřel J (1941) Chironomidarum Larvae et Nymphae IV (Genus Metriocnemus v.d. Wulp.). Acta Societatis Science Nationale Moravicae 13: 1-28. 